\title{
Suicidal and accidental drug poisoning mortality among older adults and working-age individuals in Spain between 2000 and 2018
}

Daniel Hernández-Calle ${ }^{1 *}$, Gonzalo Martínez-Alés ${ }^{2,3,4,5}$ and Teresa López-Cuadrado ${ }^{6}$

\begin{abstract}
Background: Although medication poisoning in older adults is considered an increasingly important, but preventable cause of death, it has received relatively little attention. We explored recent trends and correlates of suicidal and accidental fatal drug poisonings among older and working-age individuals using nationwide data from Spain.
\end{abstract}

Methods: We identified all 15,353 fatal drug poisonings involving decedents aged $\geq 15$ years in Spain between 2000 and 2018 and divided them by age into older adults ( $\geq 65$ years) and working-age (15-64years) individuals. For each age group, we analyzed time trends in suicidal and accidental fatal drug poisoning rates (overall and by ICD-10 drug categories) using joinpoint regressions. To understand the specific drugs classified as "Non-psychotropic/non-specified", we used 2018 data including substance-specific ICD-10 supplementary codes. We explored relevant sociodemographic correlates of suicidal and accidental fatal poisoning rates using multivariable negative binomial regressions.

Results: Between 2000 and 2018, suicidal fatal poisonings increased faster among older (from 0.19 to 0.63 per 100,000 - average annual change: $7.7 \%$ ) than working-age individuals (from 0.40 to 0.72 per 100,000 - average annual change: 3.8\%). Accidental fatal poisonings increased among older adults (from 0.25 to 2.67 per 100,000 - average annual change: 16.2\%) but decreased among working-age counterparts (from 2.38 to 1.42 per 100,000 - average annual change: - 1.9\%). Anticoagulants and cardiac-stimulants glycosides accounted for $70 \%$ of the 223 accidental fatal poisonings due to non-psychotropic/non-specified drugs registered among older adults in 2018. Roles of gender and urban dwelling in suicidal and accidental poisonings were heterogeneous across age groups.

Conclusion: Increases in suicidal drug poisonings were faster among older than working-age individuals. Accidental fatal poisonings increased only among older adults. Our findings that (i) sociodemographic correlates were heterogeneous across age groups and (ii) anticoagulant and cardiac-stimulant glycosides were particularly salient drivers of accidental poisonings among older adults have implications for prevention.

Keywords: Geriatrics, Medication error, Intentional drug poisoning, Late-life suicide

\section{Introduction}

Suicidal and accidental fatal drug poisonings among older adults constitute a major public health concern. Selfpoisoning is the most common late-life suicide attempt

\footnotetext{
*Correspondence: soydanihdez@gmail.com

1 La Paz University Hospital, Paseo de la Castellana, 261, 28046 Madrid, Madrid, Spain

Full list of author information is available at the end of the article
}

method [1]. Moreover, suicidal self-poisoning among older people has shown a rising trend over the last years $[2,3]$. Medication errors (ingestion of a wrong dose due to mistakes of the medication provider or the patient) are the most frequent cause of accidental poisoning in older adults [4]. Over the last decades, as medication regimes have become increasingly complex, the burden of health consequences and costs derived from medication errors among 
older adults has risen dramatically [5-7]. Accordingly, the World Health Organization has launched Medication without harm, an urgent call to improve prescribing, dispensing, and administration practices globally [8]. Illegal psychoactive drug overdose, traditionally considered an issue specific to younger ages, is increasingly salient among older adults, particularly due to the links between over-prescription practices and the ongoing opioid crisis $[9,10]$.

To reduce drug overdose mortality, it is critical to study accidental and suicidal poisonings together for various reasons. First, misclassification of fatal accidents as suicides and vice versa [11] is common, as determining the intentionality underlying a lethal overdose is often challenging or simply impossible [12]. Second, an important evidence-based prevention strategy for drug overdose mortality, regardless of the intentionality, is to restrict access to a small group of highly-toxic and widely available drugs that are responsible for a great proportion of overdose deaths [13]. For instance, substantial research links prescription practices to prescription and nonprescription opioid misuse and to both accidental and suicidal opioid overdose [9]. Third, even though suicidal and accidental poisonings are considered separate clinical entities, both share key actionable risk factors, such as polypharmacy, and cognitive impairment $[14,15]$.

Spain is one of the world's most rapidly aging countries [16]. Reports highlight a significant recent rise in polypharmacy among older adults [17] - importantly, polypharmacy is a major preventable risk factor for accidental poisoning [8]. Along those lines, fatal medication errors occur in $0.5 \%$ of Spain's hospital admissions constituting one of the highest fatal medication error rates in Europe [18]. In addition, increases in opioid use since 2000, especially among older adults [10], have risen concern regarding the onset of a potential opioid crisis across Europe [19]. Last, evidence suggests an ongoing upward trend of suicidal poisonings in adults in Spain [20]. However, no population-based studies have explored trends in accidental and intentional fatal drug poisonings in Spain, and fatal poisonings among older adults have not been examined, despite substantial implications for prevention efforts.

The goal of this study was to examine trends in accidental and suicidal fatal drug poisonings among older adults, overall and by specific drug involvement, comparing them to trends among working-age individuals, using Spain's nationwide population-based mortality data between 2000 and 2018.

\section{Materials and methods}

\section{Study setting, data source, and variables}

We conducted a population-based study using data on all fatal drug poisonings registered in Spain between 1 January 2000 and 31 December 2018.
All data (mortality data and population data - used for the calculation of rates) come from the National Institute of Statistics. Mortality data are based on information from the National Mortality Registry and consist of single cause-of-death mortality statistics, extracted from death certificates based on the underlying cause-of-death and issued by medical examiners (following routine autopsy if criminality is suspected). These data follow ICD coding rules: the letter and first number specifies the intentionality ascribed to the poisoning $\left(\mathrm{X}^{*}\right.$ : accidental, $\mathrm{X} 6^{*}$ : intentional, and $\mathrm{Y} 1^{*}$ : undetermined) and the second number specifies the drug involved using five categories ( ${ }^{* * 0} 0$ : nonopioid analgesics, antipyretics and antirheumatics, ${ }^{* *} 1$ : antiepileptic, sedative-hypnotic, antiparkinsonism and psychotropic drugs, "*2: narcotics and psychodysleptics, **3: other drugs acting on the autonomic nervous system, and $* * 4$ : other and unspecified drugs, medicaments and biological substances) (codes $* * 5-9$ involve non-drug substances, such as alcohol or pesticides). For instance, an accidental methadone overdose would receive code $\mathrm{X} 42$. We selected decedents aged 15 or older whose ICD-10 underlying cause-ofdeath was an accidental, suicidal, or undeterminedintent poisoning, and grouped the drugs into two broader categories: Psychotropic drugs (X41, X42, $\mathrm{X} 61, \mathrm{X} 62$, Y11, and Y12) and Non-psychotropic/Nonspecified drugs (X40, X43, X44, X60, X63, X64, Y10, Y13, and Y14).

In addition to the underlying cause of death, captured in traditional single cause-of-death mortality registries, death certificates provide information on additional contributing causes. This information is encoded using secondary ICD-10 codes in modern multiple cause-of-death mortality registries. For instance, specific substances are identified using ICD10 "Poisonings by drugs, medicaments, and biological substances" T36-50 supplementary codes [21]. An accidental overdose by methadone would indicate, in addition to the underlying cause of death code X42 (Accidental poisoning by and exposure to narcotics and psychodysleptics), a contributing cause of death code T40.3 (i.e., poisoning by methadone). In Spain, multiple cause-of-death data became available in 2018. Accordingly, we used 2018 data to further understand the role of salient substances included under the Non-psychotropic/Non-specified category [22]. Because data for this study are completely de-identified, informed consent was not required according to Spanish law.

In addition, we retrieved information on age, gender, and area of residence for each death. 


\section{Analyses}

Decedents were classified according to age into workingage individuals (15-64years) or older adults ( $\geq 65$ years). Area of residence was categorized into rural $(<10,000$ inhabitants) or urban ( $\geq 10,000$ inhabitants).

First, crude and age-adjusted mortality rates per 100,000 inhabitants were calculated using the standard European population as the reference population. We also estimated age group- and drug category-specific trends in accidental, suicidal, and undetermined-intent fatal poisonings.

Then, Joinpoint regression models were used to analyse temporal trends in fatal poisoning rates. This method uses generalized linear models, assuming a Poisson distribution, to identify inflection points (years), allowing for the quantification of temporal trends between consecutive inflection points (Annual Percent Changes $[\mathrm{APC}]$ ), as well as over the entire time period (Average Annual Percent Changes [AAPC]), both including 95\% confidence intervals $[23,24]$.

We sought to explore the possibility that accidental drug overdoses in working-age individuals may somewhat hide misclassified suicides [25]. Notably, in Spain, psychotropic drug poisonings involving use of narcotics and psychodysleptics not elsewhere specified (i.e., ICD-10 code X42) classified as accidental reliably represent true accidental overdoses, because data on these deaths are further collated by medical examiners [26]. Hence, we subtracted accidental drug poisonings including an ICD-10 code X42 from total accidental drug poisonings. Using the remaining number of drug poisonings, we estimated trends in potential misclassified suicidal overdoses over the study period and compared them to trends in drug poisonings officially classified as suicidal. Further information on ICD10 coding rules for fatal poisonings is provided in Additional file 1.

To quantify the association between sociodemographic variables and the rate of accidental and suicidal fatal poisonings, we obtained overall and age group-specific incidence rate ratios, using multivariable negative binomial regression models given the overdispersion of the outcome.

For data analysis, we used STATA 16 (StataCorp College Station TX) and Joinpoint Regression program version 4.7.0.0.

\section{Results}

Number of fatal drug poisonings in the 2000-2018 period Between 2000 and 2018, 15,353 fatal drug poisonings were registered in people aged 15 or older in Spain $18.4 \%$ corresponding to older adults. This represents an annual 808 deaths, $5.3 \%$ of the total mortality due to external causes. The most frequent underlying causes of fatal drug poisoning were accidental (72.6\%), suicidal (25.8\%), and undetermined intent (1.6\%). Fatal poisonings were most frequently attributed to non-psychotropic/ non-specified drugs, accounting for $87.7 \%$ of deaths in older adults and $62.7 \%$ in working-age individuals.

\section{Mortality trends}

During the study period, the age-adjusted rate of fatal poisonings remained relatively stable at around 2.3 per 100,000 (with slight decreasing and increasing trends, between 2000 and 2010 and 2011-2018, respectively) (Additional file 2, Fig. B.1), mainly because the rate of accidental poisonings remained roughly unchanged. Suicidal poisonings, however, increased an annual 4.1\% (95\% CI: $3.0,5.3)$, from 0.35 per 100,000 in 2000 to 0.71 per 100,000 in 2018. Undetermined-intent poisonings rates were 0.05 per 100.000 in 2000 and decreased an annual 3.5\% (95\% CI: $-6.6,-3.5)$ over the study period (A dditional file 2, Fig. B.2).

Notably, fatal poisoning rates were heterogeneous across age. Since crude and age-adjusted rates did not differ, we only present crude rates. As shown in Fig. 1, drug poisoning suicides increased from 0.19 per 100.000 in 2000 to 0.63 per 100.000 in 2018 among older adults - for an average annual $7.7 \%$ (95\% CI: $2.3,13.4)$ change; and from 0.40 per 100.000 in 2000 to 0.72 per 100.000 in 2018 among working-age individuals, for an average annual 3.8\% (95\% CI: 2.6, 5.1) change. Accidental poisonings increased from 0.25 per 100.000 in 2000 to 2.67 per 100.000 in 2018 among older adults, for an average annual $16.2 \%$ (95\% CI: $12.2,20.3)$ change; and decreased from 2.38 in 2000 to 1.42 in 2018 in working-age individuals, for an average annual $-1.9 \%$ (95\% CI: $-0.4,-3.5)$ change.

Poisonings by non-psychotropic/non-specified drugs drove the highest mortality rates in suicides in both age groups and in accidents in older adults (Fig. 2). Among working-age individuals, psychotropic drugs were initially the most salient drivers of accidental fatal poisonings, losing that position to non-psychotropic drugs after 2004 - mostly because accidental mortality due to psychotropic drugs decreased at an average annual $-17.5 \%$ (95\%: - 21.2, - 13.6) between 2000 and 2008. Suicidal poisoning mortality rates due to psychoactive drugs did not experience changes over the study period.

Figure 3 represents suicidal and accidental drug poisoning mortality rates after subtracting poisonings due to narcotics and psychodysleptics not elsewhere specified in both age groups. Among older adults, trends remained unchanged. Among working-age individuals, subtracting poisonings due to narcotics and psychodysleptics not elsewhere specified resulted on an average annual $4.2 \%$ 


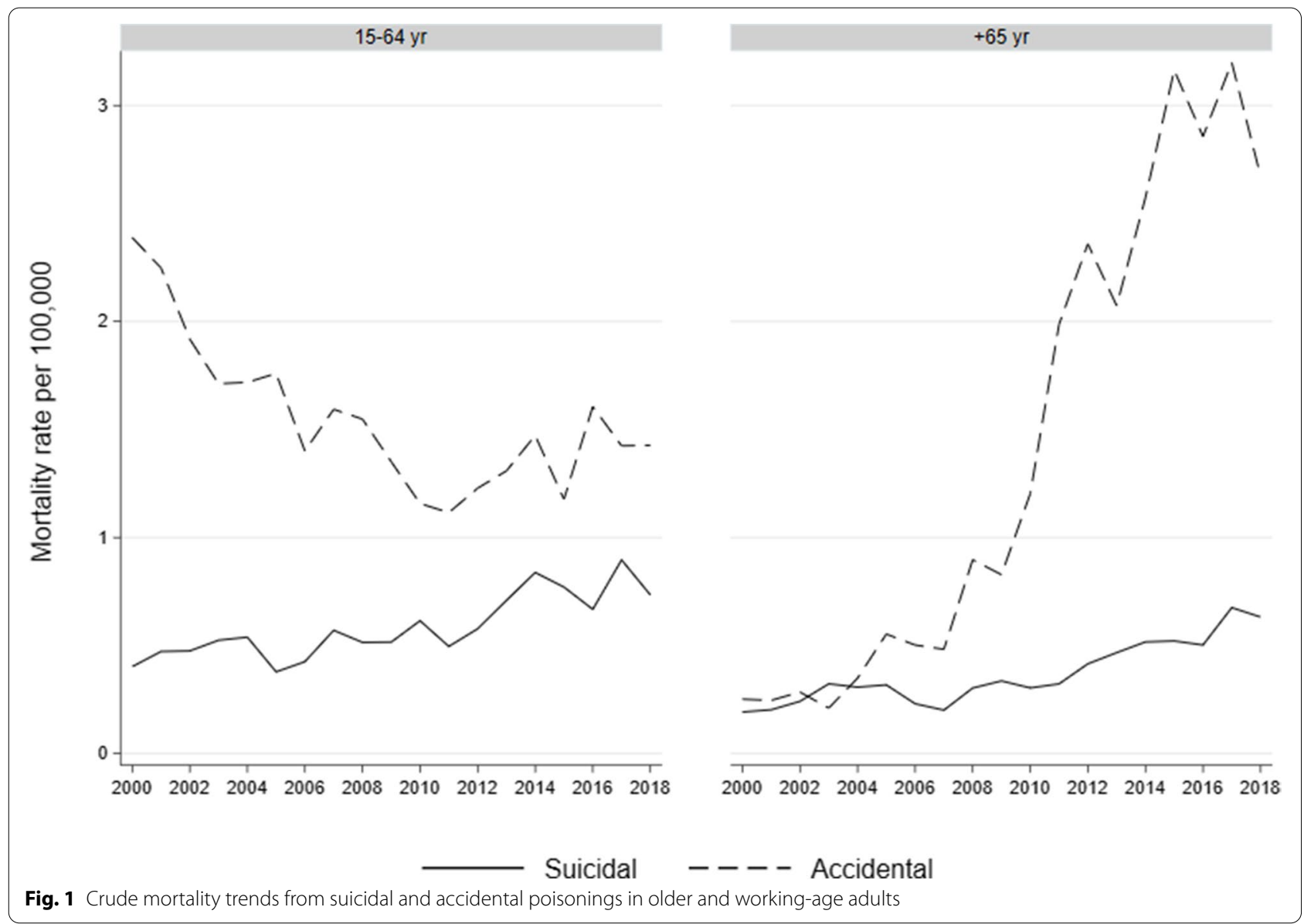

(95\% CI: 0.2, 8.5) increase in accidental poisonings and no change in suicidal poisonings.

\section{Sociodemographic characteristics of accidental and suicide fatal poisonings in the 2000-2018 period}

After adjusting for sex, area of residence, and year, incidence of fatal drug poisonings was lower among older adults in comparison to younger counterparts for suicidal poisonings (Incidence Rate Ratio: 0.74; 95\% CI: 0.66, 0.82 ) but not for accidental poisonings (IRR: 1.20; $95 \%$ CI: 0.91, 1.59).

Table 1 represents crude and adjusted IRR estimates of suicidal and accidental poisonings by sex, urbanicity, and year, stratified by age group. Among older adults, suicidal poisonings were $35 \%$ more frequent in urban areas compared to rural ones, showing no clear sexspecific variation; and accidental poisonings were $66 \%$ more frequent in rural areas and slightly more common among women. Among working-age individuals, while suicidal poisonings were $18 \%$ more frequent in rural areas, and $25 \%$ more frequent among men; accidental poisonings were not associated with urbanicity level but showed a remarkably gendered pattern: men had a 5 -fold risk increase compared to women.

\section{Specification of drugs included in the non-psychotropic/ non-specified category using 2018 multiple cause-of-death data}

Out of the 223 fatal accidental poisonings by non-psychotropic/non-specified drugs that occurred in older adults in 2018, multiple cause-of-death data allowed for the identification of specific drug codes for $76.2 \%$ of cases: $43.5 \%$ were due to anticoagulant drugs (ICD10 Code: T45.5), $26.0 \%$ to cardiac-stimulant glycosides (ICD-10 Code: T46.0) and 6.7\% to antidiabetic drugs (ICD-10 Code: T38.3) (Fig. 4). Supplementary codes were not available for most accidental poisonings involving working-age individuals, as well as for most suicides, caused by an agent included in the non-psychotropic/ non-specified category. Accordingly, we could only identify specific drug codes for less than $2 \%$ of these deaths (Additional file 3, Figs. C.1 \& C.2). 


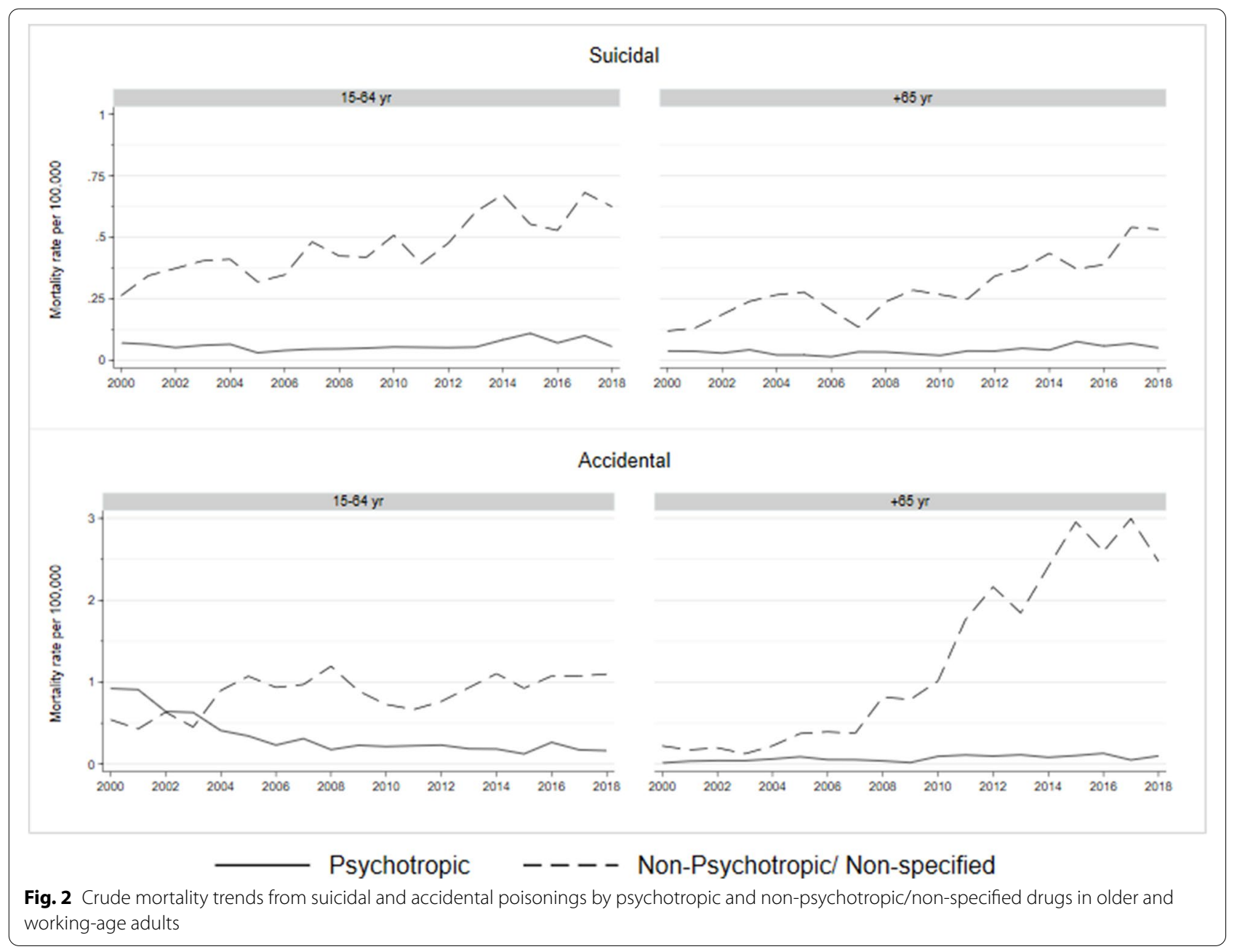

\section{Discussion}

This is the first nationwide population-based study to examine trends in mortality due to drug poisoning in older adults. To ease interpretation, we compared fatal poisonings among older and working-age individuals. We analysed both suicidal and accidental poisonings because intentionality underlying fatal poisonings is often difficult to clarify [12] and, importantly, suicidal and accidental poisonings can both be prevented by limiting access to lethal substances [11]. Our results show that, between 2000 and 2018, trends in fatal drug poisonings were heterogeneous across age groups, with overall worse trends in older adults in comparison to working-age individuals. Among older adults, on average, accidental poisonings increased by an annual $16.2 \%$ (while they decreased among working-age individuals) and intentional poisonings increased by an annual $7.7 \%$ (roughly twice as much as among working-age individuals). These findings should generate substantial attention as they enhance our understanding of unnatural death among older adults and depict alarming trends, especially in the context of the global aging population.

Our finding that suicidal poisoning increased substantially among older adults and twice as fast as among working-age counterparts, even though overall suicide mortality among the Spanish geriatric population remained stable over the same period [27], does not lend itself to easy interpretation. As mentioned, access to lethal means is considered the most salient actionable predictor of death by suicide. Accordingly, it seems plausible that increased drug accessibility may have played an important role. Since most older adults who attempt suicide use their own prescribed medication [14], recent increases in drug prescription and polypharmacy among older adults [17] seem to support this possibility. Notably, depression may have played a crucial role as it is considered one of the most important risk factors for suicide, especially in older adults [28], and is also an independent risk factor for excessive polypharmacy [29]. Furthermore, antidepressants are one of the most common 

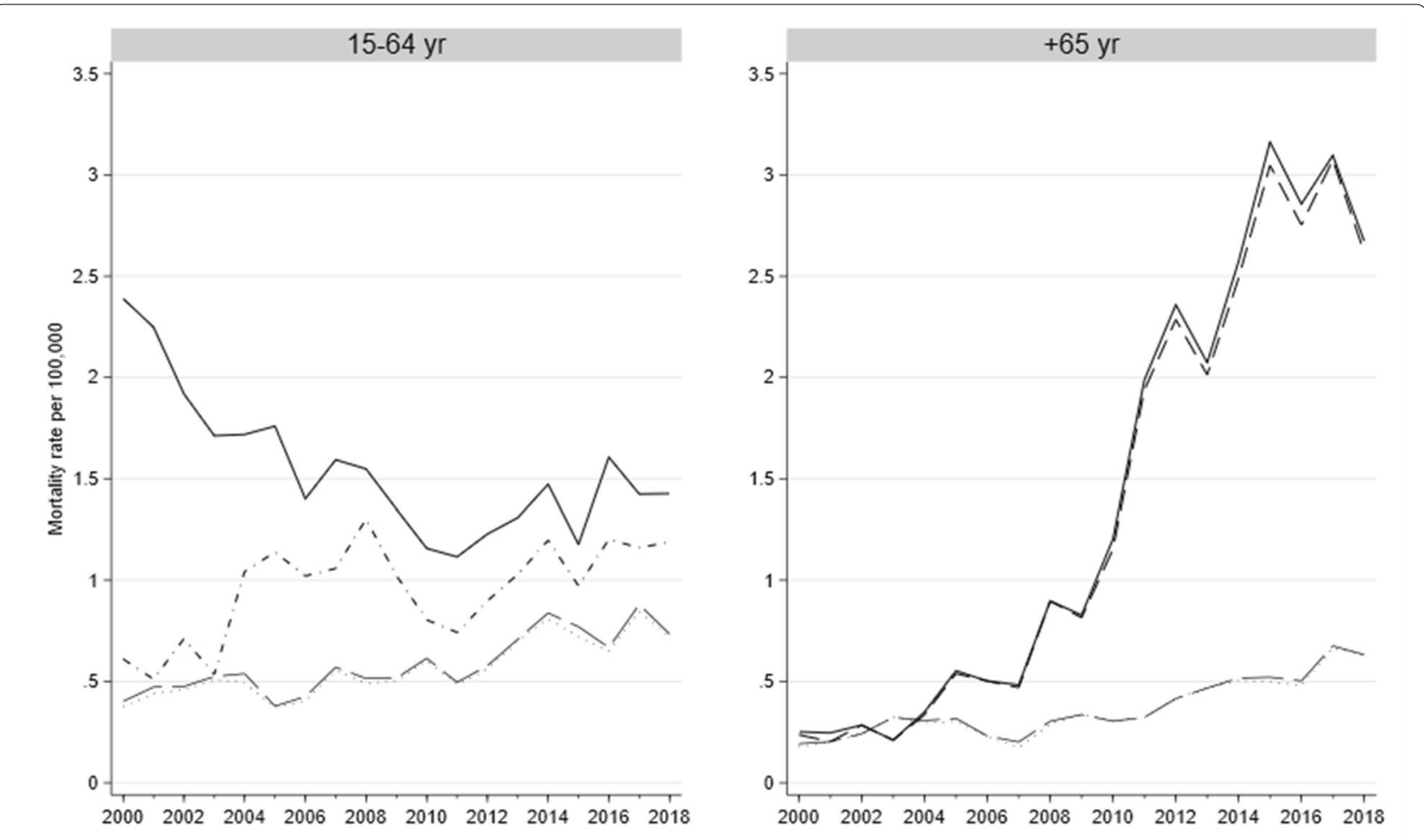

\section{- - Suicidal total \\ Suicidal without narcotics and psychodysleptics}

Accidental without narcotics and psychodysleptics

Fig. 3 Mortality trends from suicidal and accidental drug poisonings by all drugs groups (total) and all drug groups after the subtraction of codes indicating narcotics and psychodysleptics

contributors of polypharmacy and, when present, they are the second most frequently interacting drug [30]. We detected higher poisoning suicide mortality among older adults living in urban rather than rural areas, a finding that could be linked to the overall higher prevalence of depression in urban environments [31]. It also seems plausible that this finding may be related to geographical differences between rural and urban areas in access to emergency medical care, an important determinant of outcomes following acute drug poisonings [2]. We should note that the increase in suicidal poisonings may also be partially explained by progressive improvements in mortality statistics, especially given that undetermined intent poisonings decreased over the same period.

Differences between suicidal behaviours among older and working-age individuals are crucial for prevention efforts. For instance, suicide attempts seem to entail higher lethality among older adults: while, overall, it takes adults around 20 suicide attempts to die by suicide, older adults die, on average, during their 4th suicide attempt [28]. Also, older adults show a lower tendency to consult with mental health providers during suicidal crises. Moreover, many suicide risk factors specific to older adults constitute barriers for help seeking, such as social disconnectedness - an increasingly frequent problem in this age group with substantial impact on mental health [32]), visual and hearing impairment, or walking difficulties [33]. As a result, several authors have emphasized the need of specific preventive strategies that tackle these difficulties, such as improving suicide risk and depression screening in general medical services, making mental health treatment facilities more age-friendly, and early prevention of social disconnectedness through social care evaluation [28,34]. Even though suicide rates are higher in older adults, suicide prevention efforts have traditionally focused on other high risk populations (such as adolescents and young adults or people diagnosed with mental disorders), somewhat neglecting prevention of suicide among older adults [35].

Mortality due to accidental drug overdoses in older adults rose dramatically between 2000 and 2018. The low frequency of drug overdoses involving narcotics and psychodysleptics in this age group suggests that accidental deaths are mostly due to medication errors, including 
Table 1 Age-stratified unadjusted and adjusted negative binomial regressions models of accidental and suicidal poisonings mortality in older and working-age adults. All models are adjusted by study year

\begin{tabular}{|c|c|c|c|c|}
\hline \multicolumn{5}{|c|}{ Suicidal drug poisoning mortality } \\
\hline & \multicolumn{4}{|l|}{$\begin{array}{l}\text { IRR }(95 \% \mathrm{Cl}) \\
p \text {-value }\end{array}$} \\
\hline & \multicolumn{2}{|l|}{$15-64$ years } & \multicolumn{2}{|l|}{+65 years } \\
\hline & Unadjusted & Adjusted & Unadjusted & Adjusted \\
\hline \multicolumn{5}{|l|}{ Sex } \\
\hline Women & Ref & Ref & Ref & Ref \\
\hline Men & $1.29(1.12-1.50), p=0.001$ & $1.25(1.14-1.39), p<0.001$ & $1.09(0.85-1.41) ; p=0.49$ & $1.08(0.92-1.30) ; p=0.34$ \\
\hline \multicolumn{5}{|l|}{ Residence } \\
\hline Urban & Ref & Ref & Ref & Ref \\
\hline Rural & $\begin{array}{l}1.19(1.01-1.38) \\
p=0.03\end{array}$ & $\begin{array}{l}1.18(1.06-1.32) \\
p=0.003\end{array}$ & $\begin{array}{l}0.62(0.47-0.84) \\
p=0.002\end{array}$ & $\begin{array}{l}0.65(0.50-0.83) \\
p=0.01\end{array}$ \\
\hline \multicolumn{5}{|c|}{ Accidental drug poisoning mortality } \\
\hline & \multicolumn{4}{|l|}{$\begin{array}{l}\text { IRR }(95 \% \mathrm{Cl}) \\
p \text {-value }\end{array}$} \\
\hline & \multicolumn{2}{|l|}{$15-64$ years } & \multicolumn{2}{|l|}{+65 years } \\
\hline & Unadjusted & Adjusted & Unadjusted & Adjusted \\
\hline \multicolumn{5}{|l|}{ Sex } \\
\hline Women & Ref & Ref & Ref & Ref \\
\hline Men & $\begin{array}{l}5.02(4.45-5.68) \\
p<0.001\end{array}$ & $\begin{array}{l}5.02(4.45-5.66) \\
p<0.001\end{array}$ & $\begin{array}{l}0.84(0.54-1.30) \\
p=0.43\end{array}$ & $\begin{array}{l}0.88(0.74-1.01) \\
p=0.07\end{array}$ \\
\hline \multicolumn{5}{|l|}{ Residence } \\
\hline Urban & Ref & Ref & Ref & Ref \\
\hline Rural & $\begin{array}{l}0.93(0.65-1.32) \\
p=0.67\end{array}$ & $\begin{array}{l}0.95(0.84-1.08) \\
p=0.44\end{array}$ & $\begin{array}{l}1.65(1.08-2.53) \\
p=0.02\end{array}$ & $\begin{array}{l}1.66(1.51-1.83) \\
p<0.001\end{array}$ \\
\hline
\end{tabular}

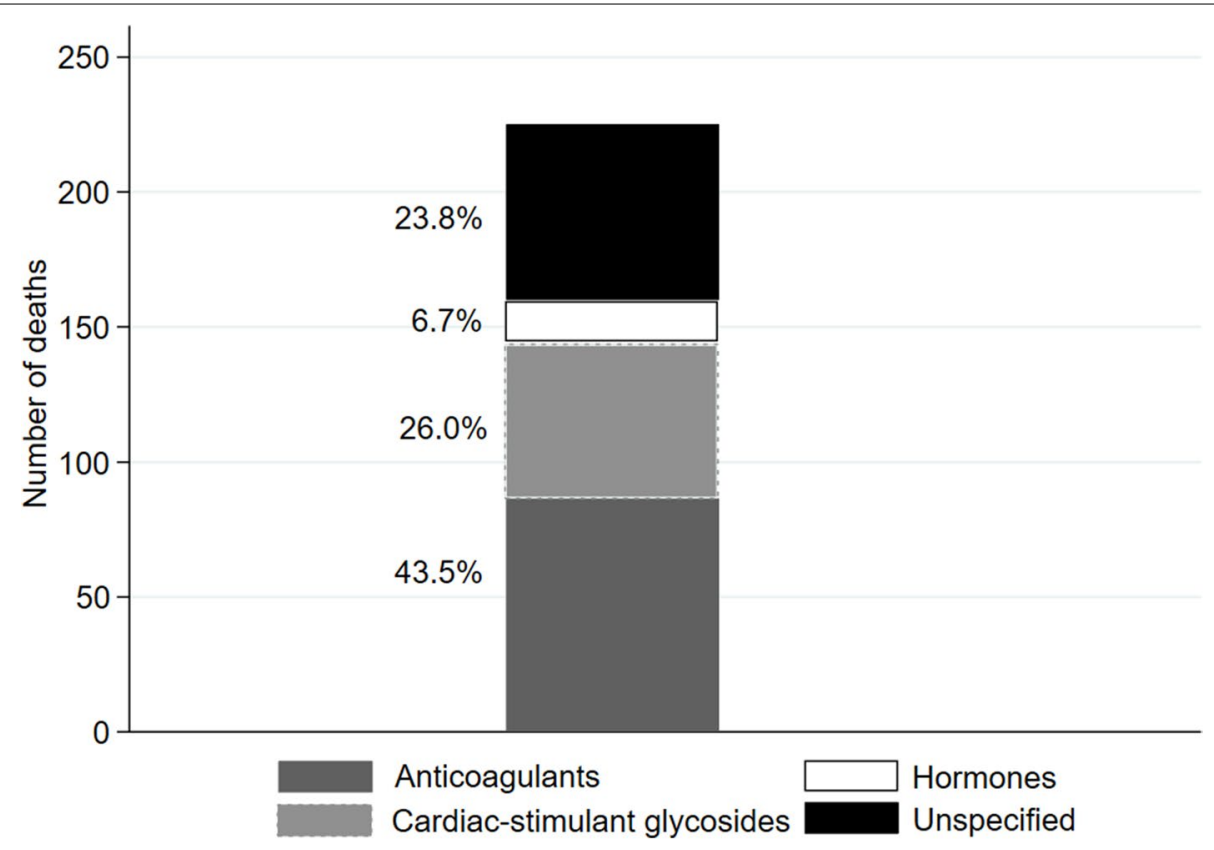

Fig. 4 Number of deaths from accidental poisonings by detailed drug type in older adults in 2018. Total bar height represents number of deaths from agents from "Non-psychotropic/non-specified" drug category, while bar subdivisions represent cases from the specific drug categories available in multiple cause-of-death data. Percentages from bar subdivisions over total bar height are shown 
errors by both providers (prescription, administration, dispensing) and patients. The frequency of medication errors is high in Spain [36] and, as in other European countries, has been increasing over recent years [37]. It is worth mentioning that The Global Burden of Disease includes deaths coded as fatal accidental poisonings as illegal drug overdoses and not under the "Adverse effects of medical treatment" section, probably leading to an overall underestimation of estimates of mortality due to medication errors, which are especially frequent in older adults [38]. Incidence of and mortality due to medication errors has been the target of a solid body of investigation. Among the most salient risk factors identified among older adults, the following stand out: dementia, because of difficulties in adequately following medication regimes [15]; chronic kidney disease, which decreases the blood clearance of drugs [39]; and polypharmacy [8].

Preventive medication error strategies seek to bolster a culture of prevention that improves coordination between the patient and the different professionals involved in the prescription process (e.g., physician, nurse, pharmacist). Actions at several levels of healthcare planning can enhance prevention of medication errors. Since most accidental poisonings occur in the home [15, 40] and nursing homes [41], the most important prevention intervention consists on encouraging patient-provider and interprofessional coordination to improve adherence to the correct dosing regimen $[8,42,43]$, as well as promoting social resources as teleassistance and domiciliary support when necessary [44]. Along these lines, improving access to healthcare is essential to ease patient-provider communication and further prevent medication errors. Accordingly, reducing formal (e.g., administrative) and informal (e.g., geographical) barriers is important for prevention purposes. In Spain, where a tax-funded health system provides universal healthcare to the population, efforts should preferentially target reducing informal differences in access to healthcare. Electronic administration systems suppose a major opportunity to improve medication reconciliation and clinical monitoring. Our results suggest that it would be particularly important to improve the implementation of electronic administration systems in rural areas, where we detected the highest mortality rate resulting from accidental drug poisonings and healthcare facilities are more scarcely distributed.

Simplifying medication regimes and limiting the prescription of a reduced group of highly toxic pharmacologic agents also should reduce mortality from poisoning in older adults, regardless of intentionality. Here, we found that roughly 9 in 10 fatal poisoning was due to drugs pertaining to the non-psychotropic/non-specified category; according to 2018 data, 43.5\% corresponded with anticoagulant agents and $26.0 \%$ with cardiotonic glycosides. In Spain, the only widespread, highly toxic drugs from these categories are, respectively, acenocoumarol and digoxin - which have also been identified as key agents driving rates of severe medication errors elsewhere $[5,45]$. Promoting use of safer pharmacological alternatives (such as so-called new oral anticoagulants beta blockers, or calcium channel blockers) when possible, may lead to a reduction in mortality from medication accidents. Our data did not allow for the specification of the drugs involved in suicidal poisonings. However, it has been reported that accidental and suicidal poisonings in this age group are frequently caused by the same drugs $[1,2,14]$. Therefore, it seems safe to conclude that a tighter control in the prescription of acenocumarol and digoxin may also reduce suicidal poisonings mortality rate. Additional measures, such as lethal means counselling or secure storing devices, also seem advisable to reduce suicidal lethal drug poisonings [46].

Working-age individuals had the highest accidental poisoning mortality rate, mainly due to a greater incidence of overdoses involving narcotics and psychodysleptics. In fact, mortality rate due to accidental poisonings exceeded the rate of suicidal poisonings in this age group. One possible explanation is that accidental fatal poisonings hide suicides to some extent, as previously suggested by other authors [25]. To further explore this possibility, we conducted a set of sensitivity analyses based on the rate of fatal accidental poisonings after excluding poisonings due to narcotics and psychodysleptics, which in Spain likely represent actually accidental overdoses, according to official sources [26]. Our finding that trends in deaths due to accidental poisonings not involving narcotics and psychodysleptics were markedly similar to trends in suicidal lethal poisonings supports this first hypothesis. A second possibility is that the non-psychotropic/non-specified category has been used in working-age individuals to encode accidental poisonings involving narcotics and psychodysleptics, something that has been suggested elsewhere [46]. Forensic records indicate that overdose mortality due to narcotics and psychodysleptics has remained stable over the last 20 years, lending support to this second hypothesis [26]. However, we should note that recreational and suicidal intentionality often coexist in overdoses involving drugs with dependence potential. Since preventive measures overlap, the difference between accidental and intentional overdoses may be simply a theoretical concept with limited intervention implications [47]. Notably, we found that psychotropic drugs mortality rate remained stable over the study period and was especially low among older adults, indicating absence of a current opioid epidemic in Spain as suggested by steady rates of opioid-related hospital emergencies [25]. 


\section{Limitations}

These study findings should be interpreted in consideration of some limitations. First, while multiple cause-ofdeath mortality data provided useful insights regarding the specific drugs involved in accidental fatal poisonings in older adults in 2018, our conclusions are limited by lack of these data for previous years and suicidal poisonings. Further analyses, as more years of multiple causeof-death mortality data become available, are warranted. Second, suicide trends to be underreported in mortality statistics as it tends to be misclassified and coded as undetermined-intent death [12]. This code, however, is infrequently used in Spanish data [46]. Nevertheless, two recent regional studies that compared registers from the National Institute of Statistics and forensic databases found data compatible with underreporting of accidental and suicidal poisonings [48, 49]. Accordingly, we cannot rule out some degree of underestimation of fatal poisonings. Third, we should acknowledge that older adults are not a homogeneous group. Notwithstanding, the limited number of suicidal and accidental poisonings among the very old (e.g., individuals aged 80 years and older) prevented us from estimating their mortality rates.

This study also has several strengths. As we used data from nationwide population-based registers, mortality rates and associations between risk factors and mortality risk should be considered valid and nationally representative. Also, the availability of a long time series ensured that mortality specific rates were not affected by changes in coding styles, a frequent bias in mortality studies based on deaths certificates [50].

\section{Conclusions}

Drug poisoning is an increasingly important cause of death in older adults in Spain. Both suicidal and accidental poisonings mortality rates have significantly risen between 2000 and 2018 among older adults, at a higher rate than among working-age individuals. This finding highlights the importance of promoting age-specific suicide and medication error preventative strategies. For instance, as acenocoumarol and digoxin are seemingly responsible of a large proportion of drug poisonings in late life, strategies to reduce their prescription and increase safety of use may lead to substantive declines of mortality due to drug poisoning in this age group. Further improvements of the granularity and comprehensiveness of mortality data are warranted to enhance understanding and prevention of drug poisoning overall and among older adults, an especially vulnerable population.

\section{Abbreviations}

ICD: International Classification of Diseases; APC: Annual Percent Changes; AAPC: Average Annual Percent Changes; IRR: Incidence Rate Ratio.

\section{Supplementary Information}

The online version contains supplementary material available at https://doi. org/10.1186/s12877-022-02806-0.

Additional file 1.

Additional file 2.

Additional file 3.

\section{Acknowledgements}

We would like to thank the Spain's National Institute of Statistics for providing us the data.

\section{Authors' contributions}

D Hernández-Calle, G Martínez-Alés, and T López-Cuadrado designed the study. D Hernández-Calle implemented the statistical analyses and wrote the first draft. $T$ López-Cuadrado supervised the statistical analyses and obtained the data. G Martínez-Alés and T López-Cuadrado revised the draft, providing important intellectual content. All authors revised and accepted the final version of the manuscript.

\section{Funding}

This study was supported by the Instituto de Salud Carlos III (grant number PI19CII/00037). The funders had neither role in study design, data collection, analysis, decision to publish, nor preparation of the manuscript.

\section{Availability of data and materials}

The data that support the findings of this study are available from National Institute of Statistics (www.ine.es) but restrictions apply to the availability of these data, which were used under license for the current study, and so are not publicly available. Data are however available from the authors upon reasonable request and with permission of National Institute of Statistics.

\section{Declarations}

\section{Ethics approval and consent to participate}

This study was performed in compliance with the relevant guidelines and legal requirements demanded in research using human data. All study procedures were approved by the Institutional Review Board of the Carlos III Institute of Health. Data were completely de-identified.

\section{Consent for publication}

Not applicable.

\section{Competing interests}

The authors declare that they have no competing interests.

\section{Author details}

${ }^{1}$ La Paz University Hospital, Paseo de la Castellana, 261, 28046 Madrid, Madrid, Spain. ${ }^{2}$ Columbia University Mailman School of Public Health, New York, NY, USA. ${ }^{3}$ Mental Health Network Biomedical Research Center (CIBERSAM), Madrid, Spain. ${ }^{4}$ Harvard University T.H. Chan School of Public Health, Boston, MA, USA. ${ }^{5}$ Hospital La Paz Institute for Health Research (IdiPAZ), Madrid, Spain. ${ }^{6}$ National Epidemiology Center, Carlos III Health Institute, Madrid, Spain.

Received: 16 April 2021 Accepted: 1 February 2022

Published online: 10 February 2022

\section{References}

1. Troya MI, Babatunde O, Polidano K, Bartlam B, McCloskey E, Dikomitis $L$, et al. Self-harm in older adults: systematic review. Br J Psychiatry. 2019;214:186-200.

2. Pillans PI, Page CB, Ilango S, Kashchuk A, Isbister GK. Self-poisoning by older Australians: a cohort study. Med J Aust. 2017;206:164-9.

3. Wang J, Sumner SA, Simon TR, Crosby AE, Annor FB, Gaylor E, et al. Trends in the incidence and lethality of suicidal acts in the United States, 2006 to 2015. JAMA Psychiatry. 2020;77:684-93. 
4. Crouch BI, Caravati EM, Mitchell A, Martin AC. Poisoning in older adults: a 5-year experience of US poison control centers. Ann Pharmacother. 2004;38:2005-11.

5. Budnitz DS, Lovegrove MC, Shehab N, Richards CL. Emergency hospitalizations for adverse drug events in older Americans. N Engl J Med. 2011;365:2002-12.

6. Walsh EK, Hansen CR, Sahm LJ, Kearney PM, Doherty E, Bradley CP. Economic impact of medication error: a systematic review. Pharmacoepidemiol Drug Saf. 2017:26:481-97.

7. Elliott RA, Camacho E, Jankovic D, Sculpher MJ, Faria R. Economic analysis of the prevalence and clinical and economic burden of medication error in England. BMJ Qual Saf. 2021;30:96-105.

8. World Health Organization. Medication without harm 2017. https://pesqu isa.bvsalud.org/portal/resource/pt/who-255263. Accessed 16 Nov 2020.

9. Alexander GC, Kruszewski SP, Webster DW. Rethinking opioid prescribing to protect patient safety and public health. JAMA. 2012;308:1865.

10. Weesie YM, Hek K, Schermer TRJ, Schellevis FG, Leufkens HGM, Rook EJ, et al. Use of opioids increases with age in older adults: an observational study (2005-2017). Front Pharmacol. 2020;11. https://doi.org/10.3389/ fphar.2020.00648.

11. Gjertsen F, Johansson LA. Changes in statistical methods affected the validity of official suicide rates. J Clin Epidemiol. 2011;64:1102-8.

12. Snowdon J, Choi NG. Undercounting of suicides: where suicide data lie hidden. Glob Public Health. 2020;15:1894-901.

13. Conwell Y, Lutz J. Lifespan development and suicide in later life. Int Psychogeriatr. 2021:33:117-9.

14. Carlsten A, Waern M, Allebeck P. Suicides by drug poisoning among the elderly in Sweden 1969-1996. Soc Psychiatry Psychiatr Epidemiol. 1999;34:609-14.

15. Mitchell RJ, Harvey LA, Brodaty H, Draper B, Close JCT. Dementia and intentional and unintentional poisoning in older people: a 10 year review of hospitalization records in New South Wales, Australia. Int Psychogeriatr. 2015;27:1757-68.

16. United Nations, Department of Economic and Social Affairs, Population Division (2020). World Population Ageing 2019 (ST/ESA/SER.A/444).

17. Hernández-Rodríguez MÁ, Sempere-Verdú E, Vicens-Caldentey C, González-Rubio F, Miguel-García F, Palop-Larrea V, et al. Evolution of polypharmacy in a spanish population (2005-2015): a database study. Pharmacoepidemiol Drug Saf. 2020;29:433-43.

18. Bouvy JC, De Bruin ML, Koopmanschap MA. Epidemiology of adverse drug reactions in Europe: a review of recent observational studies. Drug Saf. 2015;38:437-53.

19. Bosetti C, Santucci C, Radrezza S, Erthal J, Berterame S, Corli O. Trends in the consumption of opioids for the treatment of severe pain in Europe, 1990-2016. Eur J Pain. 2019;23:697-707.

20. Salmeron D, Cirera L, Ballesta M, Navarro-Mateu F. Time trends and geographical variations in mortality due to suicide and causes of undetermined intent in Spain, 1991-2008. J Public Health. 2013;35:237-45.

21. Hawton K, Simkin S, Deeks J, Cooper J, Johnston A, Waters K, et al. UK legislation on analgesic packs: before and after study of long term effect on poisonings. BMJ. 2004;329:1076.

22. World Health Organization. ICD-10: International statistical classification of diseases and related health problems. - 10th revision, Fifth edition, 2016. WHO Library Cataloguing-in-Publication Data.

23. Kim H-J, Fay MP, Feuer EJ, Midthune DN. Permutation tests for joinpoint regression with applications to cancer rates. Stat Med. 2000;19:335-51.

24. Clegg LX, Hankey BF, Tiwari R, Feuer EJ, Edwards BK. Estimating average annual per cent change in trend analysis. Stat Med. 2009;28:3670-82.

25. Snowdon J. Spain's suicide statistics: do we believe them? Soc Psychiatry Psychiatr Epidemiol. 2020. https://doi.org/10.1007/s00127-020-01948-z.

26. Observatorio Español de las Drogas y las Adicciones. Ministerio de España. Informe 2019. Alcohol, tabaco y drogas ilegales en España 2020. https:// pnsd.sanidad.gob.es/en/profesionales/sistemasInformacion/sistemalnf ormacion/pdf/2019_Informe_Indi_mortalidad.pdf. Accessed 20 Feb 2021.

27. Fernández-Cuenca R, Llácer A, López-Cuadrado T, Gómez-Barroso D. Mortalidad por causas externas en España. Bol Epidemiológico Sem. 2014;22:56-71.

28. Conwell Y. Suicide Later in Life. Am J Prev Med. 2014;47:S244-50.

29. Walckiers D, Van der Heyden J, Tafforeau J. Factors associated with excessive polypharmacy in older people. Arch. Public Health. 2015;73. https://doi.org/10.1186/s13690-015-0095-7.
30. Piccoliori G, Mahlknecht A, Sandri M, Valentini M, Vögele A, Schmid S, et al. Epidemiology and associated factors of polypharmacy in older patients in primary care: a northern Italian cross-sectional study. BMC Geriatr. 2021;21:197.

31. Purtle J, Nelson KL, Yang Y, Langellier B, Stankov I, Diez Roux AV. UrbanRural Differences in Older Adult Depression: A Systematic Review and Meta-analysis of Comparative Studies. Am J Prev Med. 2019;56:603-13.

32. Martín-María N, Caballero FF, Lara E, Domènech-Abella J, Haro JM, Olaya $B$, et al. Effects of transient and chronic loneliness on major depression in older adults: a longitudinal study. Int J Geriatr Psychiatry. 2021;36:76-85.

33. Koo YW, Kölves K, De Leo D. Suicide in older adults: a comparison with middle-aged adults using the Queensland suicide register. Int Psychogeriatr. 2017:29:419-30.

34. Blazer D. Social isolation and loneliness in older adults - a mental health/public health challenge. JAMA Psychiatry. 2020;77:990.

35. Pompili $\mathrm{M}, \mathrm{O}^{\prime}$ Connor $\mathrm{RC}$, Heeringen $\mathrm{K}$ van. Suicide prevention in the European region. Crisis. 2020. https://econtent.hogrefe.com/doi/abs/ 10.1027/0227-5910/a000665. Accessed 20 Feb 2021.

36. Guerro-Prado M, Olmo-Revuelto MA, Catalá-Pindado MÁ. Prevalence of medication-related problems in complex chronic patients and opportunities for improvement. Farm Hosp Organo Of Expresion Cient Soc Espanola Farm Hosp. 2018;42:197-9.

37. Newbould V, Le Meur S, Goedecke T, Kurz X. Medication errors: a characterisation of spontaneously reported cases in EudraVigilance. Drug Saf. 2017:40:1241-8.

38. Vos T, Lim SS, Abbafati C, Abbas KM, Abbasi M, Abbasifard M, et al. Global burden of 369 diseases and injuries in 204 countries and territories, 1990-2019: a systematic analysis for the global burden of disease study 2019. Lancet. 2020;396:1204-22.

39. Roux-Marson C, Baranski JB, Fafin C, Exterman G, Vigneau C, Couchoud $C$, et al. Medication burden and inappropriate prescription risk among elderly with advanced chronic kidney disease. BMC Geriatr. 2020;20:87.

40. Fialová D, Topinková E, Gambassi G, Finne-Soveri H, Jónsson PV, Carpenter I, et al. Potentially inappropriate medication use among elderly home care patients in Europe. JAMA. 2005;293:1348-58.

41. Szczepura A, Wild D, Nelson S. Medication administration errors for older people in long-term residential care. BMC Geriatr. 2011;11:82.

42. Mahlknecht A, Krisch L, Nestler N, Bauer U, Letz N, Zenz D, et al. Impact of training and structured medication review on medication appropriateness and patient-related outcomes in nursing homes: results from the interventional study InTherAKT. BMC Geriatr. 2019;19:257.

43. Dellinger JK, Pitzer S, Schaffler-Schaden D, Schreier MM, Fährmann LS, Hempel G, et al. Improving medication appropriateness in nursing homes via structured interprofessional medication-review supported by health information technology: a non-randomized controlled study. BMC Geriatr. 2020;20:506.

44. Parand A, Garfield S, Vincent C, Franklin BD. Carers' medication administration errors in the domiciliary setting: a systematic review. PLoS One. 2016;11:e0167204

45. Budnitz DS, Shehab N, Kegler SR, Richards CL. Medication use leading to emergency department visits for adverse drug events in older adults. Ann Intern Med. 2007;147:755-65.

46. Värnik P, Sisask M, Värnik A, Arensman E, Van Audenhove C, van der FeltzCornelis $\mathrm{CM}$, et al. Validity of suicide statistics in Europe in relation to undetermined deaths: developing the 2-20 benchmark. Inj Prev. 2012;18:321-5.

47. Oquendo MA, Volkow ND. Suicide: a silent contributor to opioid-overdose deaths. N Engl J Med. 2018;378:1567-9.

48. Serra AP, Ramírez AF, Magarolas RG, Garcia JC, Gutiérrez CV, Muñiz JM, et al. Las muertes con intervención judicial y medicolegal y su impacto en la estadística de causas de muerte en Cataluña. Rev Esp Med Leg. 2017;43:13-9.

49. Barbería E, Gispert R, Gallo B, Ribas G, Puigdefàbregas A, Freitas A, et al. Mejora de la estadística de mortalidad por suicidio en Tarragona (Cataluña, España) entre 2004 y 2012. Rev Psiquiatr Salud Ment. 2018;11:227-33.

50. Jansson B, Johansson LA, Rosén M, Svanström L. National adaptations of the ICD rules for classification--a problem in the evaluation of cause-ofdeath trends. J Clin Epidemiol. 1997;50:367-75.

\section{Publisher's Note}

Springer Nature remains neutral with regard to jurisdictional claims in published maps and institutional affiliations. 